\title{
Life-Cycle Labour Supply with Human Capital: Econometric and Behavioural Implications
}

Short Title: Labour Supply with Human Capital

\begin{abstract}
I examine econometric and behavioural implications of including human capital in the life-cycle labour supply model. With human capital, the wage is no longer the price of time - which is, instead, the wage plus returns to work experience. This has important implications: First, labour supply elasticities become functions of both preference and wage process parameters. One cannot estimate them separately. Second, the data appear consistent with larger elasticities than prior work suggests. Third, contrary to conventional wisdom, permanent tax changes can have larger effects on current labour supply than temporary changes. Fourth, effects of permanent tax changes grow over time.
\end{abstract}

Keywords: Human Capital, Labor Supply, Taxation, Life-Cycle Model, Hicks elasticity, Frisch elasticity

JEL Codes: D91, E24, H31, J22, J24

Acknowledgements: I thank the editor Kjell Salvanes and an anonymous referee for very helpful comments. This is the first of two papers that formed the basis of my Sargan Lecture to the Royal Economic Society on March 30, 2015. This research has been supported by Australian Research Council grants FF0561843 and FL110100247, by the AFTS Secretariat of the Australian Treasury and the ARC Centre of Excellence in Population Aging Research (grant CE110001029) at UNSW. But the views expressed are entirely my own.

Corresponding author: Michael Keane, Nuffield College, Oxford, OX1 1NF, UK. Email:

michael.keane@nuffield.ox.ac.uk. 
Labour supply is a fundamentally important topic in economics, and many key issues hinge on the magnitude of labour supply elasticities. To name a few: Is raising the tax rate on high earners an effective way to reduce inequality? Perhaps not, as optimal tax theory says that top rates should be lower to the extent that labour supply elasticities are larger. Can different tax rates explain differences in work hours across countries? It appears the answer may be "yes," but only if labour supply elasticities are large. Do modern macro models provide an adequate account of business cycles? Again, in most cases an affirmative answer requires fairly elastic labour supply. One could give many other examples.

Until recently, there was a broad consensus in the economics profession that labour supply elasticities are small, implying that labour supply is little affected by taxes. This view is summed up nicely by Saez, Slemrod and Giertz (2012): “... optimal progressivity of the tax-transfer system, as well as the optimal size of the public sector, depend (inversely) on the compensated elasticity of labor supply .... With some exceptions, the profession has settled on a value for this elasticity close to zero... In models with only a labor-leisure choice, this implies that the efficiency cost of taxing labor income ... is bound to be low as well."

Classic papers supporting the consensus view are MaCurdy (1981), Browning et al (1985), Altonji (1986) and Blundell and Walker (1986), who find labour supply elasticities with respect to transitory wage changes of $0.15,0.09,0.17$, and 0.03 , respectively. Responses to transitory wage changes are generally viewed as an upper bound on responses to long-lived changes, so clearly these estimates imply that labour supply elasticites are "close to zero."

Recently, the conventional wisdom has begun to break down, for two main reasons: First, as I will show, if we account for human capital, the data appear consistent with much higher labour supply elasticities than conventional wisdom suggests. Second, accounting for the extensive margin (participation and retirement decisions) also leads to larger elasticities.

In a companion paper, Keane and Wasi (2015), we develop a model that incorporates both human capital and the extensive margin. Estimation of this model unifies the two approaches, and clarifies how human capital and the extensive margin jointly affect labour supply. But in this paper I focus primarily on presenting the human capital argument.

Specifically, I examine the econometric and behavioural implications of introducing human capital - i.e., endogenous wage formation - into the standard life-cycle labour supply model of MaCurdy (1981). In the standard model, wages evolve exogenously, and savings decisions are the main source of dynamics. The assumption of exogenous wages greatly simplifies estimation of the model, as well as interpretation of labour supply elasticities. In particular, in the standard life-cycle model we have that: (i) elasticities are simple functions 
of preference parameters, and (ii) preference parameters can be estimated via a simple method-of-moments procedure that does not require one to model the wage process. ${ }^{1}$

Once we introduce human capital, these two simple features of the standard life-cycle labour supply model no longer hold. Instead, labour supply elasticities become functions of both preference parameters and the wage process. As a result, labour supply elasticities must be estimated jointly with the wage process, and, as elasticities can no longer be summarized by a few parameters, model simulations become necessary to learn about them.

Furthermore, the introduction of human capital alters the standard life-cycle model in an even more fundamentally way: If work experience builds human capital, the wage is no longer the opportunity cost of time. Instead, the price of time is the wage plus the marginal value of work experience. This divergence between the wage and the price of time has important econometric and behavioural implications. These can be categorized as: (i) the impact of accounting for human capital on estimates of preference parameters, and (ii) the impact of human capital on the behaviour of the model conditional on parameter values:

In terms of estimates, the failure to account for human capital causes conventional estimation methods to give severely biased estimates of the curvature of the utility function in leisure. This, in turn, has caused most of the prior literature to understate the willingness of workers to substitute labour inter-temporally, implying labour supply is inelastic. The only solution to this problem is structural estimation of taste and wage process parameters. ${ }^{2}$

In terms of behaviour, introducing human capital has three interesting consequences. First, labour supply elasticities become functions of age. Human capital reduces elasticities for young workers, while older workers are much more responsive to wages. Second, contrary to conventional wisdom, permanent tax changes can have larger effects on current labour supply than transitory ones. Third, the human capital mechanism amplifies the effect of permanent tax changes over time. As a result, studies that focus on short-run effects of tax reforms may greatly understate long-run labour supply elasticities.

Building on Heckman (1976) and Shaw (1989), Imai and Keane (2004) were the first

\footnotetext{
${ }^{1}$ To be clear, most labour supply research does treat wages as econometrically endogenous due to correlation with tastes for work, effects of progressive taxation, measurement error and, in dynamic models, correlation of wage innovations with lifetime wealth innovations. This is why instruments are used in the standard method-ofmoments procedure - a lá MaCurdy (1981). However, this literature still treats wages as exogenous in the sense that wage growth over the life-cycle is not affected by labour supply choices and/or the accumulation of work experience. As I will show, instruments cannot solve the problem of endogenous wage growth.

${ }^{2}$ This divergence between the wage and the price of time is the fundamental reason that instrumenting for the wage will not solve the problem of endogenous wage formation. Labour/leisure choices respond to the price of time, not the wage per se. If the two are not equal, no instrument for wages can "fix" the problem that the wage is not the correct price of time.
} 
to fully structurally estimate a life-cycle labour supply model with human capital. They showed that ignoring human capital leads to severe upward bias in estimates of the curvature of utility in leisure. In the standard model this translates directly into downward bias in the elasticity of labour supply with respect to temporary wage/tax changes. But, as I just noted, the human capital mechanism dampens labour supply responses of young workers. Thus, the Imai-Keane model implies the labour supply elasticity with respect to temporary wage/tax changes is modest for young workers, but very large for workers in their 50s and 60s.

Unfortunately, Imai and Keane failed to examine effects of permanent tax changes. These are more relevant for analysing major changes in tax policy, or differences in labour supply across countries with different tax rates. The recent paper by Keane (2015) fills this gap by using the Imai-Keane model to simulate effects of permanent tax changes.

The main contribution of the present paper is to provide a simple theoretical analysis of the econometric and behavioural implications of introducing human capital into the lifecycle model. My goal is to provide a better intuitive understanding of why labour supply elasticities are so fundamentally affected by the addition of human capital. This is important because the Imai-Keane model is rather complex, so the precise reason(s) it generates very different labour supply responses from the standard model may not be transparent.

Thus, in order to better understand the role of human capital in the life-cycle model, I adopt a much simpler framework. First, I augment the standard life-cycle model of MaCurdy (1981) with a simple learning-by-doing mechanism. This framework allows me to obtain intuitive analytical expressions for labour supply elasticities, and to see clearly how human capital affects the behaviour of the model. Second, I use a calibrated two-period version of the simple model to develop further intuition. Finally, I use this simple framework to help understand the simulation results from the original Imai-Keane model.

For example, according to the theory, permanent tax changes have larger (current) effects than transitory changes if returns to work experience are sufficiently large relative to the income effect. In the calibrated two-period model this does occur at plausible parameter values. And simulations of the Imai-Keane model show that compensated permanent tax changes do have larger effects than transitory changes, but only for young workers. This is consistent with the theory, as returns to experience are largest for the young.

In one key simulation, I find that the elasticity of current labour supply with respect to a permanent compensated tax change is 0.70 . This is an average effect over all ages. In another simulation, I find the elasticity of lifetime labour supply with respect to a permanent compensated tax change is a substantial 1.3. Both these results are in sharp contrast to the 
consensus of the prior literature that the compensated labour supply elasticity is "near zero."

To proceed, Section 1 extends the basic life-cycle model of labour supply and savings (MaCurdy (1981)) to include a simple form of human capital accumulation via learning-by doing, and discusses econometric and behavioural implications of including human capital. Section 2 uses simulations of a simple two-period version of the model to gain intuition about human capital effects. Section 3 uses simulations of the Imai and Keane (2004) model to give a quantitatively assessment of tax effects in a model with human capital. In Section 4, I discuss how failure to account for the extensive margin of labour supply can also lead to downward bias in elasticity estimates. But, as I explain, the testable implications of the extensive margin and human capital models differ in important ways. Section 5 concludes.

\section{A Simple Life-Cycle Model with Human Capital}

In this section I consider the consequences of building human capital into the standard life-cycle labour supply model of MaCurdy (1981). I consider the effect of introducing a very simple human capital accumulation mechanism that allows me to obtain intuitive closed form solutions for labour supply elasticities. Later I'll use simulations to examine the effect of introducing more complex and realistic mechanisms. As we'll see, the intuitions from the simple model carry over to the more complex cases.

In the MaCurdy (1981) formulation the period utility function is:

$$
U_{t}=\frac{C_{t}^{1+\eta}}{1+\eta}-\beta \frac{h_{t}^{1+\gamma}}{1+\gamma} \quad t=1, \ldots, T \quad \eta \leq 0, \gamma \geq 0
$$

Here $C_{t}$ is and $h_{t}$ are consumption and hours of labour supplied in period $t$, respectively. The parameter $\beta$ captures tastes for leisure. It is typically assumed to be individual specific in empirical work (but that is not necessary to make the points I wish to make here).

Given a discount factor of $\rho$, and assuming perfect-foresight, the present value of lifetime utility is given by:

$$
V=\frac{c_{1}^{1+\eta}}{1+\eta}-\beta \frac{h_{1}^{1+\gamma}}{1+\gamma}+\sum_{t=2}^{T} \rho^{t-1}\left\{\frac{c_{t}^{1+\eta}}{1+\eta}-\beta \frac{h_{t}^{1+\gamma}}{1+\gamma}\right\}
$$

Workers maximize (2) subject to the constraint that the present value of lifetime consumption equals the present value of lifetime earnings. Agents can borrow/lend across periods at interest rate $r$. In what follows I assume $\rho(1+r)=1$, in which case $C_{t}=C \forall t$. This simplifies the analysis, while not changing any of the key points. The constant level of consumption is: 


$$
C=\sum_{t=1}^{T} w_{t}\left(1-\tau_{t}\right) h_{t}(1+r)^{T-t} / \sum_{t=1}^{T}(1+r)^{T-t}
$$

Here $w_{t}$ and $\tau_{t}$ are the wage and tax rates in period $t$, respectively.

The final component of the model is the human capital production function. In order to obtain relatively simple and intuitive expressions for labour supply elasticities, I will begin by assuming an extremely simple process:

$$
w_{t}=w\left(1+\alpha \sum_{s=1}^{t-1} h_{s}\right) \quad t=2, \ldots, T ; \quad w_{1}=w
$$

Here $w$ is the initial skill endowment. The term $\sum_{s=1}^{t-1} h_{s}$ is total work experience up until the start of period $t$. The parameter $\alpha$ maps work experience into human capital. This linear in experience specification has the analytically convenient feature that an extra unit of labour supply at time $t$ raises the wage by $\alpha w$ in all future periods from $t+1$ to $T$.

It is worth emphasizing that the simple model in (1)-(4) will generate interior solutions for hours. I contrast this to a model with an operative extensive margin in Section 4.

Given the model in (1)-(4) the first order conditions of the worker's optimization problem imply:

$$
\beta h_{t}^{\gamma} / C^{\eta}=w_{t}\left(1-\tau_{t}\right)+\alpha w F_{t} \quad t=1, \ldots, T
$$

where:

$$
F_{t} \equiv \sum_{s=t+1}^{T} \frac{h_{s}\left(1-\tau_{s}\right)}{(1+r)^{s-t}} \quad F_{T}=0
$$

If $\alpha=0$, then there is no human capital accumulation via returns to work experience, and we obtain the standard model with exogenous wages. In that case we have simply:

$$
\beta h_{t}^{\gamma} / C^{\eta}=w_{t}\left(1-\tau_{t}\right) \quad t=1, \ldots, T
$$

This is the familiar "MRS" condition equating the marginal rate of substitution between consumption and leisure to after-tax wage. But once we include human capital, as in (4), the opportunity cost of time is the after-tax wage plus the effect of an extra hour of work at time $t$ on the present value of after-tax earnings in all future periods $\left(\alpha w F_{t}\right)$.

An important econometric implication of $\alpha>0$ becomes obvious if we use (5) to derive the familiar labour supply expression:

$$
\operatorname{lnh} h_{t}=\frac{1}{\gamma} \ln \left[w_{t}\left(1-\tau_{t}\right)+\alpha w F_{t}\right]+\frac{\eta}{\gamma} \ln C-\frac{1}{\gamma} \ln \beta
$$


Following MaCurdy (1981), a large literature estimates equation (7) under the assumption that $\alpha=0$, often attempting to deal with endogenous wages using instrumental variables procedures. ${ }^{3}$ The classic papers by Browning et al (1985), Altonji (1986) and Blundell and Walker (1986) mentioned in the introduction all take this approach.

The reason this literature finds inelastic labour supply is illustrated in Figure 1. This figure depicts typical paths of wages and hours over the life-cycle. ${ }^{4}$ Wages follow a familiar inverted U-shape (see Mincer (1958)), rising quickly for young workers, peaking in middle age, and declining as workers approach retirement. Hours of work also rise at young ages, but, in sharp contrast to wages, they rise quite slowly. If our model is (7) with $\alpha=0$, and we observe that hours increase much more slowly than wages in first half of the life cycle, we are essentially forced to the conclusion that labour supply is quite inelastic. ${ }^{5}$

But this classic literature fails to address the fact that, if $\alpha>0$, then the after-tax wage mismeasures the price of time. If human capital accumulation is relevant the true opportunity cost of time (OCT) is the after-tax wage plus a "human capital term" $H C \equiv \alpha w F_{t}$, so that $O C T \equiv w_{t}\left(1-\tau_{t}\right)+\alpha w F_{t}$. Figure 1 plots HC and OCT. We expect HC to be large when workers are young and to decline with age (see Heckman (1976), Shaw (1989), Imai and Keane (2004)), so the OCT path is much flatter than the wage path at young ages. Thus, if we account for human capital, the data appear consistent with much more elastic labour supply.

\subsection{The Frisch Elasticity}

Now I compare labour supply elasticities with respect to tax changes implied by the standard model vs. the human capital model. Consider first the Frisch elasticity. The Frisch is obtained from the total differential of (5) given a transitory tax change at time $t$ :

$$
\gamma \beta h_{t}^{\gamma-1} \cdot d h_{t}=w_{t} C^{\eta} \cdot d\left(1-\tau_{t}\right)+\left\{w_{t}\left(1-\tau_{t}\right)+\alpha w F_{t}\right\} \eta C^{\eta-1} \cdot d C
$$

The Frisch holds the marginal utility of consumption fixed, which in the present case is equivalent to holding consumption itself fixed. That is, set $d C=0$. Then from (8) we have:

$$
e_{F t}=\left.\frac{d \ln h_{t}}{\operatorname{dln}\left(1-\tau_{t}\right)}\right|_{d C=0}=\frac{1}{\gamma}\left[\frac{w_{t}\left(1-\tau_{t}\right)}{w_{t}\left(1-\tau_{t}\right)+\alpha \omega F_{t}}\right]
$$

\footnotetext{
${ }^{3}$ If $\alpha=0$ then (7) implies the elasticity of hours with respect to transitory wage changes (holding lifetime wealth and hence $C$ fixed) is simply $(1 / \gamma)$. This is known as the Frisch elasticity, which I discuss in detail in Section 1.1. ${ }^{4}$ Figure 1 depicts typical patterns we see across a wide range of data sets (rather than any particular data set). ${ }^{5}$ Figure 1 shows that hours do decline sharply for older workers. But, if data from the first half of the life-cycle implies inelastic labour supply, the drop in hours at older ages cannot be due to falling wages. It must be due to other factors, such as declining tastes for work or incentives created by pensions. But as we'll see, the human capital model can rationalize the entire life-cycle hours path, as it implies that elasticities increase with age.
} 
If $\alpha=0$ this reduces to the simple and familiar formula:

$$
e_{F}=\left.\frac{d \ln h_{t}}{\operatorname{dln}\left(1-\tau_{t}\right)}\right|_{d C=0}=\frac{1}{\gamma}
$$

Alternatively, equations (9) and (10) can be obtained from partial differentiation of (7).

Two contrasts between (9) and (10) are important: First, from an econometric point of view, it is important to note that in the standard model the Frisch elasticity is a function of the single preference parameter $\gamma$. This means that it is possible to estimate $e_{F}$ without modelling the wage process, as in the literature that follows MaCurdy (1981). In contrast, in (9) the Frisch elasticity is a function of the parameter $\alpha$ of the human capital production process. Thus, with human capital, labour supply and wage process models must be estimated jointly.

Second, from a behavioural point of view, we see that in the standard model the Frisch elasticity is age invariant. But in the model with human capital it varies with age $(t)$. The human capital term $\alpha w F_{t}$ in the numerator of (9) is positive and approaches 0 as $t \rightarrow T$. As a result, the Frisch elasticity tends to increase with age. ${ }^{6}$ More intuitively, note that the factor multiplying $1 / \gamma$ in (9) is the wage divided by the opportunity cost of time (OCT). For young workers the human capital investment return $\alpha w F_{t}$ is large, so the wage is much less than the OCT, and the Frisch elasticity is much less than $1 / \gamma$. But for workers close to retirement the human capital investment return $\alpha w F_{t}$ is small, and the wage is only slightly less than the OCT. Thus, the Frisch elasticity for older workers is close to $1 / \gamma$.

As we've seen, the Frisch elasticity tells us the effect of an anticipated transitory tax change that holds lifetime wealth fixed. ${ }^{7}$ But, perhaps more importantly, it also tells us the approximate effect of unanticipated transitory tax changes, because these only have small effects on lifetime wealth. Our results suggest that transitory tax changes (both anticipated and unanticipated) will have smaller labour supply effects than implied by the standard model (i.e., smaller than $1 / \gamma$ ) because they affect only a fraction of the opportunity cost of time. That is, a transitory tax does not alter the returns to human capital investment, and this diminishes its effect on labour supply.

\footnotetext{
${ }^{6}$ The increase in the Frisch elasticity with age is not necessarily monotonic. The Frisch increases from $t$ to $t+1$ iff $F_{t+1}<F_{t}$ which implies $F_{t}<h_{t+1}\left(1-\tau_{t+1}\right) / r$. But this condition must hold if the sequence $\left\{h_{t+\mathrm{s}}\left(1-\tau_{t+\mathrm{s}}\right)\right\}_{s=2, \ldots, T-t}$ is non-increasing. At almost any age $t$, it is implausible for hours to increase enough after $t+1$ for the condition to be violated - as hours are fairly flat over most of the life-cycle and actually begin to decline at older ages. A possible exception is at very young ages, where hours may be sharply increasing.

${ }^{7}$ It is worth noting that invariance of lifetime wealth is what defines the Frisch elasticity - not whether a wage or tax change is transitory. Thus, as MaCurdy (1981) emphasizes, the Frisch would also govern responses to long-term changes in the whole life-cycle wage profile - so long as those changes are either anticipated or, alternatively, compensated so that lifetime wealth is unchanged. For example, the labour supply response to anticipated wage growth from age 25 to 45 would be governed by the same $(1 / \gamma)$ elasticity derived here.
} 


\subsection{The Hicks Elasticity}

While the Frisch elasticity is useful for predicting effects of transitory tax changes, the Hicks and Marshall are relevant for predicting effects of permanent tax changes. In order to study permanent tax changes, it is convenient to assume that $\tau_{t}=\tau \forall t$, and rewrite (5) as:

$$
\beta h_{t}^{\gamma} / C^{\eta}=w_{t}(1-\tau)+\alpha w \sum_{s=t+1}^{T} h_{s}(1-\tau) /(1+r)^{s-t} \quad t=1, \ldots, T
$$

Taking the total differential (and redefining $F_{t}$ appropriately) we have:

$$
\gamma \beta h_{t}^{\gamma-1} d h_{t}=\left\{w_{t} C^{\eta}+\alpha w \frac{F_{t}}{1-\tau} C^{\eta}\right\} d(1-\tau)+\left\{w_{t}(1-\tau)+\alpha w F_{t}\right\} \eta C^{\eta-1} d C
$$

The Hicks elasticity is obtained by setting $d C$ so that a tax change does not alter a worker's consumption directly. That is, we implement a compensating transfer on the right hand side of the lifetime budget constrain (3), such that it continues to hold with equality at the initial hours vector $\left\{h_{t}\right\}_{t=1}^{T}$. Then, any change in consumption must be induced by a change in hours, and consumption is unchanged if hours remain at their initial level. ${ }^{8}$ Thus we have:

$$
d C=d C_{H} \equiv w_{t}(1-\tau) \cdot d h_{t}+\alpha w F_{t} \cdot d h_{t}
$$

The first term is the increase in current income as a result of increasing current hours, while the second term is the present value of the increase in future income as a result of increasing current hours. The latter arises from the effect of work experience on future wages.

Using (12) and (13), we obtain:

$$
e_{H t}=\left.\frac{d \ln h_{t}}{\operatorname{dln}\left(1-\tau_{t}\right)}\right|_{d C=d C_{H}}=\frac{1}{\gamma-\eta\left[C_{t}^{*} / C\right]}
$$

where:

$$
C_{t}^{*} \equiv w_{t}(1-\tau) h_{t}+\left(\alpha w h_{t}\right) F_{t}
$$

The variable $C_{t}^{*}$ could be called "effective" earnings at time $t$. It is actual earnings at $t$ plus the present value of marginal future earnings obtained due to human capital investment at $t$.

\footnotetext{
${ }^{8}$ In the static labour supply model the Hicks elasticity with respect to a wage or tax change can be obtained using either Hicks or Slutsky compensation. Hicks compensation holds maximized utility fixed, while Slutsky compensation shifts the budget constraint so that, at the initial hours level, it passes through the initial income (or consumption) level. The two are equivalent for infinitesimal wage or tax changes. In the dynamic case, we can define Hicks compensation as holding the maximized lifetime value function fixed. But this is somewhat cumbersome, because an iterative procedure is required to find this compensation level. In contrast, the Slutsky concept (i.e., consumption unchanged at the initial hours level) can be calculated directly, so it is much easier to handle, both analytically and computationally. I have compared the two approaches in simulation experiments, and find they are essentially identical for modest tax changes. See Keane (2009) for further discussion.
} 
If $\alpha=0$ then equation (14) reduces to:

$$
e_{H}=\left.\frac{d \ln h_{t}}{\operatorname{dln}\left(1-\tau_{t}\right)}\right|_{d C=d C_{H(\alpha=0)}}=\frac{1}{\gamma-\eta}
$$

which is, as noted by MaCurdy (1983), the Hicks elasticity in the standard model.

Alternatively, we can derive (15) directly using the argument in Keane and Rogerson (2015). Equation (6) implies $\ln \left[h_{t} / h_{1}\right]=(1 / \gamma) \ln \left[w_{t} / w_{1}\right]$. Thus, any policy that alters labour supply incentives but that holds the wage profile $\left\{w_{t}\right\}_{t=1, \ldots, T}$ fixed must alter hours proportionately at all ages. Furthermore, a proportional increase in hours at all ages, all else equal, increases $C$ by exactly the same proportion. ${ }^{9}$ Thus $\partial \ln C / \partial \ln h_{t}=1 \forall t$. Then, from (7) we have:

$$
\left.\frac{d \ln h_{t}}{\operatorname{dln}(1-\tau)}\right|_{c o m p}=\frac{1}{\gamma}+\left.\left.\frac{\eta}{\gamma} \frac{\partial \ln C}{\partial \ln h_{t}} \frac{d \ln h_{t}}{\operatorname{dln}(1-\tau)}\right|_{c o m p} \Rightarrow \frac{d \ln h_{t}}{\operatorname{dln}(1-\tau)}\right|_{c o m p}=\frac{1}{\gamma-\eta}
$$

Two contrasts between (14) and (15) are important. First, from an econometric point of view, it is important to note that in the standard model the Hicks elasticity is a function of two preference parameters, $\gamma$ and $\eta$. Thus, it is possible to estimate $e_{H}$ without explicitly modelling the wage process, given data on wages, hours and consumption, as in MaCurdy (1983). In contrast, in equation (14) the Hicks elasticity is a function of the human capital production process parameter $\alpha$. Thus, to uncover the Hicks elasticity, one must jointly estimate models of labour supply, consumption and the wage process.

Second, from a behavioural point of view, we see that in the standard model the Hicks elasticity is age invariant. But in the human capital model it varies with age. How it varies depends on the effective earnings variable $C_{t}^{*}$. The first component of $C_{t}^{*}$, current earnings, has a hump shape over the life-cycle, while second component, the human capital investment return $\left(\alpha w h_{t} F_{t}\right)$, declines with age. Thus, it is ambiguous (and an empirical matter) how the Hicks elasticity varies from youth to middle age. But both components of $C_{t}^{*}$ approach zero as workers approach retirement. Thus, the Hicks elasticity for older workers is close to $1 / \gamma^{10}$ In fact, both the Frisch and Hicks elasticities converge to $(1 / \gamma)$ as $t \rightarrow T$. It is interesting that while the human capital mechanism can only dampen the Frisch elasticity, it can either dampen or amplify the Hicks, depending on the size of $C_{t}^{*}$ relative to $C$.

\footnotetext{
${ }^{9}$ This argument does not hold with human capital. A proportional increase in hours at all ages generates a more than proportional increase in $C$, because human capital will be augmented.

${ }^{10}$ It is important to recall that our model in (1)-(4) generates interior solutions for hours. Thus, what I describe as "workers approach retirement" actually means that $w_{t}(1-\tau) h_{t}$ falls to very low levels, as does $C_{t}^{*}$. For workers at low levels of earnings income effects become trivial, so the Hicks elasticity approaches the Frisch.
} 
In the standard model it is well known that the Frisch elasticity must be greater than or equal to the Hicks; that is, $(1 / \gamma) \geq 1 /(\gamma-\eta)$. There is equality only in the case of no income effects $(\eta=0)$. The reason the Frisch elasticity exceeds the Hicks is that Frisch compensation is greater than Hicks compensation. But with the introduction of human capital the ranking becomes ambiguous and age dependent.

Comparing (9) and (14), we see that the Hicks elasticity at age $t$ exceeds the Frisch if:

$$
\frac{1}{\gamma-\eta\left[C_{t}^{*} / C\right]}>\frac{1}{\gamma}\left[\frac{w_{t}\left(1-\tau_{t}\right)}{w_{t}\left(1-\tau_{t}\right)+\alpha w F_{t}}\right] \quad \Rightarrow \quad \alpha w F_{t}>\frac{(-\eta)}{\gamma} \frac{C_{t}^{*}}{C} w_{t}\left(1-\tau_{t}\right)
$$

Strikingly, in the case of no income effects $(\eta=0)$ this inequality must hold, so the Hicks elasticity must exceed the Frisch. This is because permanent tax changes have a larger effect on the price of time than transitory, and so a larger pure substitution effect. But income effects work in the opposite direction. Thus, in general, (16) implies that the Hicks elasticity will exceed the Frisch if the return to human capital investment $\left(\alpha w F_{t}\right)$ is sufficiently large relative to the product of the income effect and effective earnings $\left(-\eta C_{t}^{*}\right)$. To see why, note that as $\alpha \uparrow$ the Frisch falls, while as $-\eta C_{t}^{*} \downarrow$ the Hicks increases.

Thus, once we introduce human capital, it is possible that permanent compensated tax changes will have larger effects on current labour supply than transitory tax changes. This result contradicts the conventional wisdom that transitory tax changes should have larger effects than permanent changes. The fundamental reason for this surprising outcome is that a permanent tax change has a greater effect on the opportunity cost of time than a transitory tax change (as it affects not only the current wage but also returns to human capital investment).

There are two important implications of this result: First, it may undermine the argument for transitory tax cuts as an economic stimulus measure, while lending some empirical support to the supply side argument for permanent compensated tax cuts. Second, because the Frisch has been considered an upper bound on the Hicks, the large literature based on MaCurdy (1981) that finds small Frisch elasticities has been interpreted as implying small values of the Hicks as well - which in turn implies small welfare effects of taxation. But if the Frisch > Hicks relation fails to hold, this conclusion no longer follows.

\subsection{The Marshallian Elasticity}

Finally, we consider the Marshallian or uncompensated elasticity. The allows $d C$ to incorporate both incremental earnings due to changes in hours and the income effect due to the change in the tax rate. In particular, we have:

$$
d C=d C_{M} \equiv w_{t}(1-\tau) \cdot d h_{t}+\alpha w F_{t} \cdot d h_{t}+\frac{E_{t}}{1-\tau} \cdot d(1-\tau)
$$


where $E_{t}$ denotes the present value of after-tax earnings:

$$
E_{t} \equiv \sum_{s=t}^{T} \frac{w_{s}(1-\tau) h_{s}}{(1+r)^{s-t}}
$$

Using (12) and (17), we obtain:

$$
e_{M t}=\left.\frac{d \operatorname{lnh} h_{t}}{\operatorname{dln}\left(1-\tau_{t}\right)}\right|_{d C=d C_{M}}=\frac{1+\eta\left[E_{t} / C\right]}{\gamma-\eta\left[C_{t}^{*} / C\right]}
$$

Notice the denominator of the Marshall elasticity is identical to the Hicks. The income effect comes in through the additional $\eta\left[E_{t} / C\right]$ term in the numerator. If $\alpha=0$ then (19) reduces to:

$$
e_{M}=\left.\frac{d \ln h_{t}}{\operatorname{dln}\left(1-\tau_{t}\right)}\right|_{d C=d C_{M(\alpha=0)}}=\frac{1+\eta}{\gamma-\eta}
$$

which is the Marshallian elasticity in the standard model.

We can also derive (20) directly. Using (6) to substitute for $h_{t}$ in (3) we obtain:

$$
\ln C=\frac{1+\eta}{\gamma-\eta} \ln (1-\tau)+\frac{\gamma}{\gamma-\eta} \ln k, \quad k \equiv \sum_{t=1}^{T}\left(w_{t}\right)^{\frac{1+\gamma}{\gamma}} \beta^{-\frac{1}{\gamma}}(1+r)^{T-t} / \sum_{t=1}^{T}(1+r)^{T-t}
$$

Then equation (6) - or, equivalently, equation (7) with $\alpha=0$ - implies that:

$$
\operatorname{lnh} h_{t}=\frac{1}{\gamma} \ln \left[w_{t}(1-\tau)\right]+\frac{\eta}{\gamma} \frac{1+\eta}{\gamma-\eta} \ln (1-\tau)+\frac{\eta}{\gamma} \frac{\gamma}{\gamma-\eta} \ln k-\frac{1}{\gamma} \ln \beta
$$

which gives:

$$
\frac{d \ln h_{t}}{\operatorname{dln}(1-\tau)}=\frac{1}{\gamma}+\frac{\eta}{\gamma} \frac{1+\eta}{\gamma-\eta}=\frac{1+\eta}{\gamma-\eta}
$$

Comparing (19) and (20) we see that the introduction of human capital again has two effects: (i) it makes the Marshallian elasticity a function of both preference and wage process parameters, and (ii) it makes the Marshallian elasticity a function of age.

Of course, the income effect term $\eta\left[E_{t} / C\right]$ in (19) is non-positive, so the Marshallian elasticity must be less than (or equal to) the Hicks. The Marshallian elasticity is positive only if $1+\eta\left(E_{t} / C\right) \geq 0$. Thus, even the sign of the Marshallian elasticity may vary with age.

Strikingly, it is ambiguous whether the Marshallian elasticity is greater or less than the Frisch. Comparing (9) and (19), we see that the Marshall is greater than the Frisch if:

$$
\alpha w F_{t}>\left[\frac{(-\eta)}{\gamma} \frac{C_{t}^{*}}{C}-\eta \frac{E_{t}}{C}\right] w_{t}\left(1-\tau_{t}\right) \frac{1}{1+\eta\left(E_{t} / C\right)} \quad \text { and } \quad 1+\eta\left(E_{t} / C\right)>0
$$


If there are no income effects $(\eta=0)$, this condition reduces to $\alpha w F_{t}>0$, so the Marshall must exceed the Frisch if there are any human capital effects. Again, this is because a permanent tax change has a larger effect on the opportunity cost of time than a transitory one.

Once we allow for income effects, we see that the threshold in (21) is greater than that in (16). Compared to the Hicks case, the human capital effect $\alpha w F_{t}$ must be stronger in order for the Marshall to exceed the Frisch. Finally, as we discussed in Section 1.2, the term $C_{t}^{*} / C$ may be greater than or less than one, and the same is true of $E_{t} / C$. But it is clear that both $C_{t}^{*}$ and $E_{t}$ approach zero as workers approach retirement. As a result, the Marshall, Hicks and Frisch all converge to the same value $(1 / \gamma)$ as workers get older. ${ }^{11}$

\subsection{Quantifying the Bias From Ignoring Human Capital}

As I noted in the introduction, if human capital is important but we ignore it in estimation, it will cause bias in estimates of preference parameters and labour supply elasticities. But how severe is this problem likely to be? Is it quantitatively important? To address this question, it is useful to work with a simple two-period version of our model.

If $T=2$ then the first order conditions for hours are:

$$
\beta_{1} h_{1}^{\gamma} / C^{\eta}=w_{1}\left(1-\tau_{1}\right)+\rho \alpha w h_{2}\left(1-\tau_{2}\right) \quad \beta_{2} h_{2}^{\gamma} / C^{\eta}=w_{2}\left(1-\tau_{2}\right)
$$

Note that at $t=1$ the opportunity cost of time is augmented by the term $\rho \alpha w_{1} h_{2}\left(1-\tau_{2}\right)$, which captures the effect of an hour of work at $t=1$ on the present value of earnings at $t=2$. Here I let tastes for work $\beta_{t}$ have an age subscript to create a source of stochastic variation in hours.

Using (22) we can obtain the following hours change equation:

$$
\ln \left(h_{2} / h_{1}\right)=\frac{1}{\gamma} \ln \left[\frac{w_{2}\left(1-\tau_{2}\right)}{w_{1}\left(1-\tau_{1}\right)+\rho \alpha w h_{2}\left(1-\tau_{2}\right)}\right]+\varepsilon
$$

where $\varepsilon \equiv(1 / \gamma) \ln \left(\beta_{1} / \beta_{2}\right)$ is a shock to tastes for work (as in MaCurdy (1981)).

Equation (23) makes clear why the conventional method of regressing hours growth on wage growth understates labour supply elasticities and overstates $\gamma$. The effective wage rate at $t=1$ is understated by the failure to account for the human capital term $\rho \alpha w_{1} h_{2}\left(1-\tau_{2}\right)$ in the denominator of (23). Thus, effective wage growth from $t=1$ to $t=2$ is exaggerated. As a result, the responsiveness of hours of work to changes in the price of time is understated.

We can get a better sense of the magnitude of the problem by considering a regression of hours changes on wage changes:

\footnotetext{
${ }^{11}$ Note that income effects become negligible as workers approach retirement and reduce their hours to low levels (see footnote 10 for further discussion).
} 


$$
\ln \left(h_{2} / h_{1}\right)=\Gamma \ln \left[\frac{w_{2}\left(1-\tau_{2}\right)}{w_{1}\left(1-\tau_{1}\right)}\right]+v
$$

Running the population regression (assuming data generated by (23)) we obtain:

$$
\Gamma=\frac{1}{\gamma} \ln \left[\frac{w_{2}\left(1-\tau_{2}\right)}{w_{1}\left(1-\tau_{1}\right)+\rho \alpha w h_{2}\left(1-\tau_{2}\right)}\right] / \ln \left[\frac{w_{2}\left(1-\tau_{2}\right)}{w_{1}\left(1-\tau_{1}\right)}\right]
$$

Thus, our estimate $\Gamma$ of $(1 / \gamma)$ is biased downward by a factor equal to the ratio of the rate of growth in the effective wage rate to the rate of growth in the observed wage rate. As the Frisch, Hicks and Marshall elasticities all have the preference parameter $\gamma$ in their denominators, inferences about all three elasticities will be biased downwards.

To assess how large the bias is likely to be, we need a plausible value for the $\rho \alpha w h_{2}$ term in (25). Given a two period model where each period corresponds to 20 years, it is plausible in light of existing estimates that $\alpha w h_{1}$, the percent growth in the wage over the first 20 years of the working life, is on the order of $33 \%$ to $50 \% .^{12}$ So take the conservative value of $\alpha w h_{1}=33 \%$. A reasonable figure for hours growth over the first 20 years of the working life is roughly $20 \%$ (see, e.g., Imai and Keane (2004) or the descriptive regressions in Pencavel (1986)). So assume that $h_{2}$ is $20 \%$ greater than $h_{1}$. Then $\alpha w h_{2}$ is roughly $40 \%$. Let $\rho$ $=1 /(1.03)^{20}=0.554$. Then we obtain $\rho \alpha w h_{2}=22 \%$. Finally, assume that $\tau_{1}=\tau_{2}$, and normalize $w_{1}=1.0$. In this example, wage growth is $33 \%$, but the growth in the opportunity cost of time is only $1.33 / 1.22=9 \%$.

Given these parameter values, the bias term in $(25)$ is $\ln (1.33 / 1.22) / \ln (1.33)=0.30$. Thus, according to $(25)$ our estimates of $(1 / \gamma)$ will be biased down by a factor of roughly 3.3 . So, for reasonable parameter values, the bias from ignoring human capital is substantial.

An important point is that instruments cannot be used to solve the problem of endogenous wage formation. To see this rewrite (23) as:

$$
\ln \left(h_{2} / h_{1}\right)=\frac{1}{\gamma} \ln \left[\frac{w_{2}\left(1-\tau_{2}\right)}{w_{1}\left(1-\tau_{1}\right)}\right]+\left\{\varepsilon+\frac{1}{\gamma} \ln \left[\frac{w_{1}\left(1-\tau_{2}\right)}{w_{1}\left(1-\tau_{1}\right)+\rho \alpha w h_{2}\left(1-\tau_{2}\right)}\right]\right\}
$$

The composite error term (in curly brackets) includes the ratio of the first period wage to the opportunity cost of time. Any variable that affects the growth rate of after-tax wages will be correlated with this ratio as well. This invalidates any instrument that predicts wage growth.

\footnotetext{
${ }^{12}$ For instance, using the PSID, Geweke and Keane (2000) estimate that for men with a high school degree, average earnings growth from age 25 to 45 is $33 \%$ (most of which is due to wage growth). For men with a college degree the estimate is $52 \%$. They also find that earnings growth essentially ceases after about age 45 .
} 


\section{Simulations of a Simple Two-Period Model}

In this section, I use a simple two-period version of the model of Section 1 to develop further intuition for how human capital affects behaviour of the life-cycle model.

\subsection{Two-Period Model Calibration}

To calibrate the two-period model, we may think of each period as 20 years out of a 40-year working life (e.g., 25 to 44 and 45 to 64 ). Then, an annual interest rate of $3 \%$ implies a 20 year interest rate of $r=.806$, and a discount factor of $\rho=1 /(1+r)=0.554$. In the baseline model I set the tax rates to $\tau_{1}=\tau_{2}=.40$.

Turning to the wage function, in contrast to the simple function assumed for analytical convenience in Section 1, equation (4), here I assume the more realistic:

$$
w_{2}=w_{1} \exp \left(\alpha h_{1}-\kappa \frac{h_{1}^{2}}{100}-\delta\right) \quad \Rightarrow \quad \ln w_{2}=\ln w_{1}+\alpha h_{1}-\kappa \frac{h_{1}^{2}}{100}-\delta
$$

This is a Mincer-type earnings function, with $w_{1}$ as the skill endowment, a quadratic in hours (experience), and a depreciation term $\delta$, which causes earnings to fall if a person does not work sufficient hours in period one. Keane and Wolpin (1997) find depreciation is important.

I consider three values of the CRRA parameter $\eta$ that governs strength of the income effect, $\eta \in\{-.50,-.75$ and -1.0$\}$. The values $\eta \approx-.50$ and $\eta \approx-.75$ are from Keane and Wolpin (2001) and Imai and Keane (2004), which are among the few studies to estimate life-cycle models with savings, human capital, and CRRA utility. ${ }^{13}$ The value $\eta=-1.0$ is often used in macro models (if $U=\log (C)$ income and substitution effects cancel, giving balanced growth).

Of course, $\gamma$ is the subject of great controversy. Many macro economists argue values of about $(1 / \gamma)=2$ are needed to explain business cycles using standard models (see Prescott $(1986,2006))$. But most micro estimates of $(1 / \gamma)$ using the MaCurdy (1981) approach are quite small - at least for men - i.e., .30 or less (see Keane (2011)). Imai and Keane (2004) is a major exception, as they estimate $(1 / \gamma)=3.7$. They argue, for the reasons discussed earlier, that failure to account for human capital led prior work to severely understate $(1 / \gamma) .{ }^{14}$ Given the controversy over $\gamma$, I consider a wide range of values, $\gamma \in\{0,0.25,0.50,1,2,4\}$. But I often focus on $\gamma=0.50$, given that past debates have focussed on the plausibility of this value.

Finally, $\beta$ is merely a scaling parameter. I normalize $\beta$ so that $h=100$ corresponds

\footnotetext{
${ }^{13}$ Shaw (1989) used translog utility, so her estimates are not useful for calibrating (1). Goeree, Holt and Palfrey (2003) present experimental evidence, as well as evidence from field auction data, in favor of $\eta \approx-.4$ to -.5. Bajari and Hortacsu (2005) estimate $\eta \approx-.75$ from auction data.

${ }^{14}$ Another rare exception is French (2005), who obtains 1.33 for 60 year olds in the PSID. Recall from our results in Section 1 that downward bias in estimates of $(1 / \gamma)$ should be less for older workers. Estimates for women tend to be higher (e.g., Heckman and MaCurdy (1982) obtain 2.3 for married women in the PSID).
} 
(roughly) to full-time work and $h=50$ to part-time work. ${ }^{15}$ I calibrate the model so that: (i) a person must work at least part-time at $t=1$ for the wage not to fall at $t=2$, and (ii) the return to additional work falls to zero at $h=200$. Given these constraints, the wage function reduces to:

$$
w_{2}=w_{1} \exp \left(\alpha h_{1}-\frac{\alpha}{4} \frac{h_{1}^{2}}{100}-\frac{175}{4} \alpha\right)
$$

Thus, the single parameter $\alpha$ determines how work experience maps into human capital.

To obtain the wage growth of $33 \%$ to $50 \%$ observed for men from age 25 to age 45, it is necessary to set $\alpha$ in the .008 to .010 range. But I also consider a range of other $\alpha$ values, to learn how behaviour of the model changes when human capital is more or less important.

The calibrated model generates reasonable hours growth. For instance, the model with $\alpha=.008, \eta=-.50$, and $\gamma=.50$ gives a $10 \%$ increase in hours from $t=1$ to $t=2$. As a point of comparison, for the 1956-65 birth cohort, McGrattan and Rogerson (1998) report average hours growth of $12 \%$ from ages $25-34$ to ages $35-44$. Of course, a simple two-period model must abstract from the subsequent decline in hours as older workers approach retirement.

\subsection{Standard Model without Human Capital}

Now I use the two-period model to simulate labour supply elasticities. Table 1 gives results for models with $\eta=-.75$ (the Imai-Keane (2004) estimate). The first four rows show results for the standard model with no human capital $(\alpha=0)$. The lower rows show results for progressively higher values of $\alpha$. The columns correspond to different values of $\gamma$.

The left panel of Table 1 shows elasticities with respect to temporary tax changes at $t=1$. The first two rows show uncompensated (total) and compensated (Hicks) elasticities. The next two rows show the Frisch elasticity calculated in the conventional way as hours growth divided by wage growth. The right panel of Table 1 shows elasticities with respect to permanent tax changes (i.e., changes that apply in both periods).

Consider first the standard model $(\alpha=0)$ with $\gamma=.50$. In this case, the Marshallian elasticity is $(1+\eta) /(\gamma-\eta)=0.20$, the Hicks (compensated) elasticity is $1 /(\gamma-\eta)=0.80$, and the Frisch elasticity is $1 / \gamma=2.0$. As we see in the first three rows of Table 1 , the simulated values of these elasticities correspond closely to the theoretical values. ${ }^{16}$ And, comparing the left and right panels of Table 1, we see that, as expected, elasticities with respect to transitory tax cuts are much greater than those with respect to permanent tax cuts.

Notably, elasticities with respect to transitory tax changes at $t=1$ are smaller than the Frisch. With only two periods, a change in the $t=1$ tax rate leads to a non-trivial change in

\footnotetext{
${ }^{15}$ Specifically, in each simulation I set $\beta$ so optimal hours are 100 in the model without human capital $(\alpha=0)$. The initial wage $w_{1}$ is also set to 100 . These values were chosen purely for ease of interpreting the results.

${ }^{16}$ Slight differences arise because we are taking finite difference derivatives (i.e., we increase $(1-\tau)$ by $1 \%$ ).
} 
consumption. Keane (2009) shows that, in the standard model, the uncompensated and compensated labour supply elasticities with respect to temporary tax changes at $t=1$ are:

$$
\frac{\partial \operatorname{lnh} h_{1}}{\partial \ln \left(1-\tau_{1}\right)}=\left[\frac{1+\eta}{\gamma-\eta}\right]-\left.\left[\frac{\eta}{\gamma-\eta} \frac{1+\gamma}{\gamma} \frac{1}{2+r}\right] \quad \frac{\partial \ln h_{1}}{\partial \ln \left(1-\tau_{1}\right)}\right|_{c o m p}=\frac{1}{\gamma} \frac{1}{2+r}+\frac{1}{\gamma-\eta} \frac{1+r}{2+r}
$$

in the two-period case. These equations give values of 0.84 and 1.228 , which align closely with the values of 0.835 and 1.222 obtained in the simulation.

\subsection{Models with a Small Human Capital Effect}

Adding a small human capital effect leads to important changes in results. The second panel of Table 1 shows results with the human capital effect set at the low level of $\alpha=.001$. Strikingly, even this small value renders the conventional method of estimating the Frisch elasticity - i.e., taking the ratio of hours growth to wage growth - completely unreliable. ${ }^{17}$

For instance, with $\gamma=0.50$ and tax rates fixed, hours increase by $0.72 \%$ from $t=1$ to $t=2$ while the wage increases by $3.25 \%$. Taking the ratio, the conventional method would infer a Frisch elasticity of only 0.221 . In contrast, the true value of $(1 / \gamma)$ is 2.0 and the compensated elasticity with respect to a transitory tax cut in period one is 1.104 .

One might surmise that the conventional method of estimating the Frisch is severely biased because wage growth in this model is entirely endogenous - i.e., it results entirely from human capital investment. One might further suppose that if the data contained a source of exogenous variation, such as an exogenous tax change, one could infer $\gamma$ more reliably.

Surprisingly, this intuition is fundamentally flawed. The row labelled "Frisch $(\Delta \operatorname{tax})$ " in Table 2 reports Frisch elasticities calculated in the conventional manner in a regime with a temporary $1 \%$ tax cut in $t=1$. In the $\gamma=0.50$ case the estimate is -.478 , which is not even the correct sign! Why? The tax cut causes labour supply to increase in period 1, which, in turn, increases the wage in period 2. But despite the wage increase, hours decline in period 2. This is because (i) the tax cut is removed, and (ii) the human capital part of the OCT is removed. Thus, although the wage is higher at $t=2$, the OCT is lower, leading to lower hours.

This discussion clarifies why a strictly exogenous shift in the wage path cannot exist in a model with human capital. A higher after-tax wage at $t=1$ increases hours at $t=1$, but this raises the wage at $t=2$ via the human capital effect. So a $t=1$ tax cut does not exogenously change in the wage profile, as the wage at $t=2$ is altered by the behavioural response.

\footnotetext{
${ }^{17}$ Of course, econometric studies that estimate the Frisch elasticity by regressing hours changes on wage changes use more complex IV techniques, designed to deal with measurement error in wages, heterogeneity in tastes for work, and unanticipated wage changes. We do not have any of those problems here, so the appropriate estimator boils down to just taking the ratio of hours growth to wage growth.
} 


\subsection{Models with Plausible Human Capital Effects}

Now I consider more plausible returns to work experience, which requires $\alpha$ in the range of .008 to .010 (see Section 2.1). The first notable result is that total and compensated elasticities with respect to transitory tax changes drop substantially as human capital becomes more important. For example, if $\gamma=0.50$, the compensated elasticity falls from 1.222 in the no human capital case to .606 in the $\alpha=.008$ case (see left panel of Table 1 ). This is consistent with our finding in Section 1.1. A that human capital reduces responses to temporary tax cuts.

In Sections 1.2-1.3 we found that effects of human capital on Marshallian and Hicks elasticities are ambiguous. In the right panel of Table 1, we see that total and compensated elasticities with respect to permanent tax changes tend to decline as $\alpha$ increases. However, the decline is quite modest (and there are a few exceptions).

Thus, our simulations imply human capital dampens transitory more than permanent tax effects. This creates the possibility that permanent tax changes may have larger effects than transitory. In fact, if $\alpha=.008$ and $\gamma=0.50$, the compensated elasticity of labour supply at $t=1$ with respect to a temporary tax cut is 0.606 , but that with respect to a permanent tax cut is greater, 0.698. So, it is indeed possible for permanent tax changes to have larger effects than transitory at plausible parameter values (at least for compensated changes).

Finally, in Table 1 we see the usual method of estimating the Frisch elasticity gives values 3 to 4 times smaller than compensated elasticities for both permanent and temporary tax changes. Even more striking, in the $\alpha=.008, \gamma=0.50$ case, the uncompensated elasticity for a $t=1$ tax cut is 0.312 , while the estimates of the Frisch elasticity are 0.177 and 0.198 . This illustrates how the low estimates of the Frisch elasticity in the literature cannot be viewed as an upper bound on compensated or even uncompensated elasticities.

\subsection{Sensitivity of Results to Income Effects}

Table 2 reports results for a model with $\eta=-.50$, the value estimated by Keane and Wolpin (2001). This implies weaker income effects than in the previous simulations. Focus again on the $\gamma=0.50$ case. In the model without human capital $(\alpha=0)$, the uncompensated elasticity with respect to a temporary tax cut at $t=1$ is, as expected, much greater than that with respect to a permanent tax cut (1.03 vs. 0.50). But with plausible returns to work experience $(\alpha=.008)$, the uncompensated elasticity with respect to a permanent tax cut is greater than that with respect to a temporary tax cut ( 0.445 vs. 0.420$)$.

These results are consistent with the theoretical analysis in Sections 1.2 and 1.3. There we saw that permanent tax changes can have larger effects than transitory if the return to human capital investment is large enough relative to the income effect. The hurdle is, of 
course, greater for uncompensated tax changes. In Table 1 we saw cases where compensated permanent tax effects exceeded transitory effects. In Table 2, with weaker (but still plausible) income effects, we see this outcome for un-compensated tax changes as well.

Other Table 2 results are broadly similar to those in Table 1. Elasticities with respect to transitory tax changes decline sharply as the human capital effect $(\alpha)$ grows stronger. But elasticities with respect to permanent tax changes decline only modestly. The conventional method of estimating the Frisch elasticity produces sharply downward biased estimates that are much smaller than the true elasticities with respect to transitory tax changes.

So far, I considered cases where substitution effects dominate income effects $(\eta>-1)$. Macro models often assume $\log (C)$ utility $(\eta=-1)$ to generate balanced growth. Thus, it is also interesting to consider this case. To conserve space I only summarize the results:

Of course, the uncompensated elasticity with respect to permanent tax cuts is always zero, as income and substitution effects cancel. If $\gamma=0.5$, the uncompensated elasticities of $t=1$ labour supply with respect to transitory tax cuts are $0.24,0.18$ and 0.13 in the $\alpha=0.008,0.010$ and 0.012 cases, respectively. So, as expected, with log utility transitory tax cuts must have larger effects than permanent in the un-compensated case.

But for compensated elasticities the outcome is reversed. Elasticities with respect to transitory tax cuts are $0.56,0.48$ and 0.42 in the $\alpha=0.008,0.010$ and 0.012 cases, respectively, but for permanent tax cuts the figures are $0.57,0.56$ and 0.55. A similar pattern holds for all $\gamma$ from 0.25 to $4 .^{18}$ Thus, for plausible $\alpha$ and $\gamma$, permanent tax effects are larger than transitory.

\section{Quantitative Assessment of the Role of Human Capital}

Here I provide a quantitative assessment of the role of human capital in the life-cycle model. Key issues are (i) magnitudes of labour supply elasticities, (ii) how elasticities vary with age, (iii) elasticities with respect to permanent vs. transitory taxes, and (iv) long-run vs. short-run elasticities. The simple model of Sections 1-2 helps to develop intuition and to see qualitative patterns, but for serious quantitative assessment we need a richer model with some claim to external validity. For this purpose I will turn to the model of Imai and Keane (2004).

\subsection{The Structure and Fit of the Imai-Keane Model}

To my knowledge, Imai and Keane (2004) is the only micro model that attempts to fit asset, hours and wage data over the whole working life. ${ }^{19}$ Because it generates life-cycle

\footnotetext{
${ }^{18}$ For example, if $\gamma=2.0$, the compensated elasticity of $t=1$ labour supply with respect to transitory tax cuts is $0.27,0.24$ and 0.22 for the $\alpha=0.008,0.010$ and 0.012 cases, respectively. But for permanent tax cuts these figures are $0.32,0.31$ and 0.31 . Thus, the permanent tax effects are $20 \%$ to $40 \%$ greater than transitory effects. ${ }^{19}$ Two other papers that fit assets, hours and wages are Van der Klauuw and Wolpin (2008) and Keane and Wolpin (2001). The former simulates behavior of older workers, while the later focuses on youth.
} 
paths from age 20 to 65 , it can be used to simulate both age-specific labor supply elasticities and the long-run effects of permanent tax changes. The basic setup of the model is as follows:

The Imai-Keane model assumes the same utility function as MaCurdy (1981). There are annual decision periods from age 20 to 65 . At age 65 agents must retire, and there is a terminal value function that depends on assets (to create a motive for retirement savings). The model contains a complex human capital production function that generalizes that in Section 2 in several ways. For instance, there is complimentarity between human capital and work hours in the production of skill. Human capital production parameters are allowed to vary in a flexible way with education and age. Unlike the simple models of sections 1-2, uncertainty is introduced. Wages are stochastic and wage shocks show persistence over time. Agents can borrow/lend across periods, and there are age varying tastes.

The model is fit to white males from the NLSY79 born in 1958-65 and followed from age 20 to 36. Imai and Keane (2004) document that it produces a good in-sample fit to assets, hours and wages, both in terms of typical age profiles and dynamics/transition rates (e.g., it captures observed persistence in individual wages quite accurately).

The model also generates reasonable out-of-sample forecasts. For instance, it predicts an hours decline of $53 \%$ from ages $45-54$ to $55-64 .{ }^{20}$ This is close to the $47 \%$ figure for this cohort projected by McGrattan and Rogerson (1998). Also, if simulated data from the ImaiKeane model is used to estimate conventional labour supply functions, it gives conventional (i.e., small) elasticities. As the model provides a good fit to wage, hours and asset patterns both in and out-of-sample - it seems credible to use it to predict labour supply responses.

\subsection{Simulations of the Model - Short-Run Labour Supply Elasticities}

Table 3 reports elasticities of current hours with respect to transitory and permanent tax changes. I refer to these as "short-run elasticities." In the columns labelled "transitory," the tax increase applies for one year at the indicated age. I report results for cases where the tax change is either unanticipated or anticipated. An unanticipated tax change has a (small) wealth effect, but an anticipated change has no wealth effect, so we have a pure Frisch effect. Note that the Frisch gives a very accurate approximation to transitory tax effects. A small divergence between them is only apparent when workers are in their 50s and 60s.

As we see in Table 3, the Frisch elasticity increases substantially with age, from only 0.30 at age 20 to 1.96 at age 60 . This agrees with the prediction of Section 1.1: transitory

\footnotetext{
${ }^{20}$ A limitation of the Imai-Keane model is it assumes interior solutions for hours, so it cannot generate complete retirement prior to age 65 . But this limitation should not be exaggerated. In the 2008 CPS, $70 \%$ of men aged 5564 still worked, and 52\% of men aged 62-64 still worked (see Purcell (2009)).
} 
taxes have small effects at young ages because they only affect a fraction of the opportunity cost of time (i.e., the current after-tax wage, not returns to human capital investment). But, as workers age and the return to human capital investment falls, the Frisch elasticity increases.

Now, consider short-run elasticities with respect to permanent tax changes. These are presented in the two right-most columns of Table 3, which show uncompensated (Marshall) and compensated (Hicks) effects. In the simulations, the tax rate changes un-expectedly at the indicated age and the change lasts until age 65 . The table reports the effect on current labour supply in the year the tax change is first implemented.

Again, elasticities vary substantially by age. The compensated (Hicks) elasticity is 0.64 at age 20, drops slightly to 0.46 at ages 35 to 40 , and then rises sharply to 2.09 at age 60 . Similarly, the uncompensated elasticity is 0.14 at age 20 , drops to 0.10 at age 35 , and rises sharply to 1.88 at age 60. Frisch, Hicks and Marshall elasticities are all close to 2 at age 60.

As I discussed in Sections 1.2-1.3, the change in the Hicks and Marshall elasticities from youth to middle age is ambiguous, but both should approach the Frisch as workers near retirement. The patterns in Table 3 are consistent with this prediction. There are two reasons the three elasticities converge at older ages: First, work hours drop to low levels so income effects become small. Second, the effect of experience on human capital becomes negligible, so this is no longer a source of difference between permanent and transitory tax effects.

Overall, the Imai-Keane model implies that the aggregate short-run Hicks elasticity, averaged over all ages, is 0.70 . Workers in their 50s and 60s account for half of the overall response. It is interesting to compare the short-run tax effects predicted by the model with results from the literature on tax reforms. Chetty (2012) pools estimates from many existing studies, most using the short-run effects of tax reforms as the source of identification, and obtains a Hicks elasticity of $0.58 .^{21}$ The Imai-Keane prediction of 0.70 is a bit higher, but this may be because many studies screen out older men, who have the largest elasticities. Thus, the Imai-Keane model prediction is in the ballpark of the quasi-experimental evidence.

As we saw in Section 1, another important implication of the human capital model is that permanent tax effects can exceed transitory tax effects - but whether this actually occurs is an empirical question. A key result in Table 3 is that, at least for young workers, compensated permanent tax increases do have larger effects than transitory. For instance, at

\footnotetext{
${ }^{21}$ Chetty (2012)'s bounds imply a Hicks elasticity of 0.33 on the intensive margin and 0.25 on the extensive margin. As the Imai-Keane model does not distinguish between the intensive and extensive margins (i.e., it is fit to data on total annual hours), I take the sum (0.58) as the relevant point of comparison. To bound the intensive margin elasticity Chetty uses 15 studies, based on tax reforms in the US, UK, Iceland, Sweden and Denmark. The extensive margin elasticity is inferred from 11 studies that examine US, UK and Danish tax reforms, EITC expansions, and cross-country tax comparisons.
} 
age 25 the Hicks elasticity is 0.54 while the Frisch is only 0.36 . By the mid-30s the two elasticities are roughly equal. Only in the 40s do transitory tax effects become clearly larger.

This finding is consistent with results from Section 1. Permanent tax cuts can have larger short-run effects than transitory, as they alter both the current wage and the human capital term in (5), while a transitory tax only affects the current wage. But as workers age, returns to work experience fall. Eventually, the human capital effect is too small for the bound in (16) to be satisfied, and transitory taxes begin to have larger effects.

Finally, as we saw in Section 1.3 it is also theoretically possible for uncompensated permanent tax effects to exceed transitory tax effects. But the results in Table 3 indicate that this does not occur in practice (because the income effect is too strong).

\subsection{Simulations of the Model - Long-Run Tax Effects}

In this section I consider the effect of permanent changes in tax rates on labour supply over the whole working life. I refer to these as "long-run elasticities." In Table 4 I use the Imai-Keane model to simulate the impact of a permanent change in the tax rate on labour earnings that starts at age 20 and lasts through age 65 .

Consider first the elasticity of lifetime hours from age 20 to 65 . As we see in Table 4, the long-run compensated elasticity is a very substantial 1.3. Notably, the Hicks elasticity implied by the Imai-Keane parameter estimates in the standard model without human capital is, from equation $(15), e_{H}=1 /(\gamma-\eta)=1 /(.262+.736) \approx 1.0$. Thus, the human capital mechanism amplifies the compensated elasticity of lifetime hours by $30 \%$ (from 1.0 to 1.3 ).

Table 4 also reports elasticities of hours at selected ages. As we see, a permanent tax hike reduces hours much more at older ages than at young ages. The effect of the tax grows with age for two reasons: First, as workers get older the after-tax wage makes up a larger fraction of the opportunity cost of time. Second, a permanent tax hike slows the rate of human capital accumulation, which produces a "snowball" effect on wages:

If a worker reduces his hours at time $t$, he will have a lower wage at time $t+1$. This causes him to work even less at time $t+1$, leading to a lower wage at $t+2$, etc.. If we use the model to simulate a $5 \%$ permanent tax increase starting at age 25 , then by age 40 a worker's wage is reduced by only $1.0 \%$, but by age 55 his wage is reduced by $3.6 \%$, and by age 65 the reduction is $11.6 \%$. This lowering of pre-tax wages creates an additional work disincentive, beyond the direct effect of the tax. And this disincentive becomes quite large at older ages.

To summarize, we find a short-run (average) Hicks elasticity of 0.70 but a long-run Hicks elasticity of 1.3. This result has important implications for the growing literature that estimates labour supply elasticities by looking at responses to major tax reforms (see Saez et 
al (2011) or Keane (2011) for reviews). This literature adopts a difference-in-difference approach and generally focuses on short-run responses. The results presented here imply that a short-run focus may cause one to seriously understate long-run responses to taxes.

\section{Other Modifications to the Standard Model: Human Capital vs the Extensive Margin}

As I noted in the introduction, the conventional wisdom that labour supply elasticites are "close to zero" has recently begun to break down for two main reasons: The first is the role of human capital, while the second is the extensive margin. Here I discuss the role of the extensive margin, and compare predictions of the extensive margin vs. human capital models.

Some key papers that emphasize the extensive margin are French (2005), Chang and Kim (2006), Prescott et al (2009), Rogerson and Wallenius (2009) and Erosa et al (2014). The key feature in Rogerson-Wallenius (RW) is a non-convex mapping from work hours to labour services. If a person works $h_{t}$ hours at age $t$, he produces $h_{t}^{*}=\max \left\{h_{t}-\bar{h}, 0\right\} e(t)$ efficiency units of labour. Here $\bar{h}$ is the minimum hours a person must work to be productive. And $e(t)$ is an exogenous lifecycle productivity path. RW set $e(t)=1-e_{1}|t-40|$, so that productivity rises to a peak at age 40 and falls afterwards. They use the same utility function as in (1), with $\eta=-1$, and consider behaviour of the model for a range of $\gamma$ values.

In the RW model workers' primary decision is the length of the working life - i.e., when to enter the workforce and when to retire. But, conditional on work, hours are rather stable at a full-time level. The non-convex mapping from hours to labour services drives this pattern, as it is inefficient to work part-time.

At young and old ages, when productivity $e(t)$ is relatively low, workers are close to indifferent between non-participation and full-time work. Hence, labour supply is highly elastic for young and old workers, as a small wage or tax change can change their discrete participation decision. In contrast, middle age workers with high productivity are not close to the margin of indifference between work and non-participation. And the technology dictates that they should work full-time, so their labour supply is quite insensitive to taxes.

Given this set-up, RW show the compensated labour supply elasticity is independent of the preference parameter $\gamma$. If $\gamma$ is large, the labour supply response to a permanent tax increase is almost entirely due to shortening of the work life. If $\gamma$ is small, more of the response involves changes in hours. But the overall response is the same in either case. ${ }^{22}$

The RW model is stylized, as it is meant to clarify the role of the extensive margin. Erosa et al (2014) extend it by allowing for heterogeneity in tastes for leisure, fixed costs of

\footnotetext{
22 Thus, non-convexity severs the direct link between the preference parameters and labor supply responses to tax changes, just as human capital does. Labour supply responses depend on both technology and preferences.
} 
work, a 4-month decision period, search frictions, credit constraints, and more realistic specifications of both life-cycle productivity variation and the non-linear mapping from hours to labour services. ${ }^{23}$ Their model matches many key features of the wage and hours data for males between the ages of 25 and 61 in the PSID and SIPP.

Erosa et al. (2014) find that the aggregate labour supply elasticity in response to a transitory (unanticipated) wage change is 1.75 at the 4 -month frequency. ${ }^{24}$ Of this effect, 1.08 is on the extensive margin. There is a strong age pattern: For non-college workers the transitory elasticity is 2.01 for the 25-34 age group, 1.62 for the 35-44 age group, 1.90 for the 45-54 age group and 2.74 for the 55-61 age group. ${ }^{25}$

In contrast, the transitory elasticity in the Imai-Keane model increases from only 0.36 at age 25 to 1.74 at age 60 (see Table 3 column 1). This is a fundamental distinction: In the human capital model the effect of transitory wage/tax changes is small for young workers but rises steadily with age. In the extensive margin model it follows a U-shape and is large for both young and older workers.

As for permanent wage/tax changes, the Erosa et al. (2014) model generates a Hicks elasticity of 0.44 for aggregate hours, which is smaller than the 0.75 found by RW. But the restriction of the sample to men aged 25-61 may cause Erosa et al. to understate the Hicks elasticity as we expect large responses from the young and old in an extensive margin setting.

The Hicks elasticity can be decomposed into 0.55 on the intensive margin and -0.11 on the extensive margin. The latter is negative because the tax increase causes people to retire later. This contrasts with RW, where permanent tax increases shorten the working life.

Notice the Erosa et al model implies that aggregate transitory tax effects are 4 times greater than permanent compensated tax effects (i.e., 1.75 vs. 0.44). In sharp contrast, the Imai-Keane model implies they are similar (both around 0.70). In fact, the Imai-Keane model implies that permanent and transitory tax effects are roughly comparable at almost all ages (compare Table 3 columns 1 and 4 ). ${ }^{26}$ This is because: (i) human capital dampens transitory tax effects substantially at younger ages, while (ii) at older ages the Frisch and Hicks converge as income effects of permanent tax changes grow small.

To summarize, there are two key differences between the extensive margin and human capital models: (i) the former implies that transitory tax effects are very large for both

\footnotetext{
${ }^{23}$ Both fixed costs and non-linear earnings help to generate an operative extensive margin. Erosa et al (2014) find they are complementary in magnifying extensive margin elasticities. The 4-month decision period also increases the importance of the extensive margin.

${ }^{24}$ At an annual frequency, the elasticity with respect to transitory wage changes is 1.54 .

${ }^{25}$ For college workers the pattern is very similar, except shifted down by roughly 0.65 at every age.

${ }^{26}$ The only real exception is at ages 20 to 25 , when the Hicks is actually quite a bit larger than the Frisch.
} 
young and old workers, while the latter implies they are small for young workers and only large for old workers, and (ii) the former implies that transitory tax effects are much greater than permanent in general, while the latter implies they are fairly similar at almost all ages.

Thus, while both human capital and extensive margin models generate labour supply elasticities that are substantially greater than conventional wisdom suggests, they do so in different ways. Specifically, these models have quite different implications for (i) the age pattern of elasticities, and (ii) relative magnitudes of elasticities for permanent vs. transitory tax changes. In a companion paper, Keane and Wasi (2015), we develop a model that incorporates both human capital and the extensive margin in a single framework. This allows us to investigate how human capital and the extensive margin jointly affect labour supply.

\section{Conclusion}

This paper has explored the behavioural and econometric implications of extending the standard life-cycle labour supply model to include human capital. With human capital investment, the wage no longer equals the opportunity cost of time. Rather, the opportunity cost of time is the wage plus the return to work experience. This has important implications for how workers respond to taxes, and for proper estimation of labour supply elasticities.

There are two key econometric implications of adding human capital to the life-cycle model. First, labour supply elasticities are no longer functions of preference parameters alone - they also depend on parameters of the wage process. As a result, the conventional GMM procedure of estimating elasticities and preferences without the need to specify the wage process is no longer valid. One must specify and estimate the wage process jointly.

Second, the conventional GMM procedure that ignores human capital will lead to severely upward biased estimates of the degree of curvature of utility in hours. This, in turn, leads to downward biased estimates of labour supply elasticities. In fact, given human capital, the data are consistent with much larger labour supply elasticities than conventional wisdom suggests. For example, the Imai and Keane (2004) model implies a compensated (Hicks) labour supply elasticity of 0.70 in the short-run (holding human capital fixed) rising to 1.3 in the long run (as the higher tax rate reduces the rate of human capital accumulation).

The introduction of human capital also has important behavioural implications. First, labour supply elasticities become functions of age. The Frisch is reduced considerably for young workers due to human capital investment concerns. But it grows substantially with age. Age paths of the Hicks and Marshall are ambiguous, but they also rise to a level close to 
the Frisch as workers near retirement. Thus, a strong prediction of the human capital model is that labour supply elasticities are much greater for older workers than for younger workers.

Second, contrary to conventional wisdom, permanent tax changes can have larger effects on current labour supply than transitory. A permanent tax alters not only the current wage but also returns to human capital investment, so it has a larger effect on the opportunity cost of time. However, a permanent tax also has a larger income effect. So permanent tax changes have larger effects than transitory changes iff returns to human capital investment are sufficiently large relative to income effects. Simulations of the labour supply model of Imai and Keane (2004) imply that this does occur for relatively young workers.

Third, in the presence of human capital, effects of permanent tax changes on labour supply grow over time. This is because a permanent tax slows the rate of human capital accumulation, which reduces pre-tax wages in the long-run. ${ }^{27}$ This has important implications for the growing literature that estimates labour supply elasticities by looking at responses to major tax reforms. The short-run focus of most of this literature may lead it to understate responses to taxes in the long-run.

One limitation of the analysis based on the model in Imai and Keane (2004) is that it assumes interior solutions for hours. ${ }^{28}$ Of course, this is also true of MaCurdy (1981) and most of the male labour supply literature. It is not clear if these simplifications would affect the main results presented here, but building corner solutions into the model is an important avenue for future research. The evidence suggests, however, that corners solutions lead to higher labour supply elasticities (see Keane and Rogerson (2012)). Hence, it seems unlikely that including an extensive margin and/or retirement decisions would alter the main message of the paper - that labour supply elasticities are larger than conventional wisdom suggests.

A second limitation is the models presented here ignore schooling, and consider the behaviour of workers conditional on their having entered the labour force. But as noted by Keane and Wolpin $(2000,2010)$, changes in the tax/transfer system that reduce rewards to working will also reduce educational attainment. So accounting for this additional channel would presumably magnify the long-run tax effects on human capital found here.

\footnotetext{
${ }^{27}$ Thus, in the long-run, after-tax wages fall by more than the amount of the tax increase. For example, the ImaiKeane model implies a long-run compensated elasticity of 0.54 at age 25, but this rises to 3.9 at age 60 . Thus, a permanent tax increase pivots the entire hours profile, shifting relatively more labour supply to younger ages. ${ }^{28}$ For instance, while the Imai-Keane model correctly generates that average hours fall by about $50 \%$ from ages 45-54 to ages 55-64, it cannot generate that roughly 30\% of males aged 55-64 do not work (see Purcell (2009)). Instead, it approximates this by having some workers reduce hours to low levels. Also, the model imposes retirement at age 65 , rather than treating it as a choice.
} 
A third limitation is that the models employed here assume a particular investment mechanism (learning-by-doing) while others may be operative, such as on-the-job training (OJT) - see Heckman (1976). But, as emphasized by Becker (1962), OJT models are similar to learning models in key respects: The observed wage (i.e., earnings/hours) differs from the opportunity cost of time (productivity) because only a fraction of work hours are spent in production. The rest is spent learning. Learning time falls with age, so wages grow more slowly than the opportunity cost of time. This is exactly the same problem that causes labour supply elasticities to be underestimated if we ignore learning-by-doing.

This paper is part of an emerging literature exploring mechanisms that may have caused prior work to understate labour supply elasticities. Besides human capital, other potentially important mechanisms include the extensive margin (Erosa et al (2014), Rogerson and Wallenius (2009), French (2005), Kimmel and Kniesner (1998)), liquidity constraints (Domeij and Floden (2006)), uninsurable wage risk (Low and Maldoom (2004)), and fixed costs of adjustment (Chetty (2012)). An important task for future research is to assess the relevance of these mechanisms. A step in this direction is the companion paper Keane and Wasi (2015) that incorporates human capital, the extensive margin, retirement decisions, Social Security, pension benefits and progressive taxation.

In conclusion, while conventional wisdom says labour supply elasticities are small, more dissent from that position is emerging.

\section{Michael P. Keane}

University of Oxford and University of New South Wales 


\section{References}

Altonji, J. (1986). 'Intertemporal Substitution in Labor Supply: Evidence from Micro Data’, Journal of Political Economy, vol. 94 (3, Part 2), pp. S176-S215.

Bajari, P. and Hortacsu, A. (2005). 'Are Structural Estimates of Auction Models Reasonable? Evidence from Experimental Data', Journal of Political Economy, 113(4), pp. 703741.

Becker, G. (1962). 'Investment in Human Capital: A Theoretical Analysis', Journal of Political Economy, 70(5, Part 2), pp. 9-49.

Blundell, R. and Walker, I. (1986). 'A life cycle consistent empirical model of family labour supply using cross-sectional data', Review of Economic Studies, 53(4), pp. 539-58.

Browning, M., Deaton, A. and Irish, M. (1985). 'A profitable approach to labor supply and commodity demands over the life-cycle', Econometrica, vol. 53(2), pp. 503-44.

Chetty, R. (2012). 'Bounds on elasticities with optimization frictions: a synthesis of micro and macro evidence on labor supply', Econometrica, vol. 80(3), pp. 969-1018.

Chang Y., and Kim, S.B. (2006). 'From individual to aggregate labor supply: a quantitative analysis based on a heterogeneous agent macroeconomy', International Economic Review, vol. 47(1), pp. 1-27.

Domeij, D. and Floden, M. (2006). 'The labor supply elasticity and borrowing constraints: why estimates are biased', Review of Economic Dynamics, vol. 9(2), pp. 242-262.

Erosa, A., Fuster, L. and Kambourov, G. (2014). 'Towards a micro-founded theory of aggregate labor supply', Working Paper 516, Dept. of Economics, Univ. of Toronto.

French, E. (2005). 'The effects of health, wealth and wages on labour supply and retirement behaviour', The Review of Economic Studies, vol. 72(2), pp. 395-427.

Geweke, J. and Keane, M. (2000). 'An empirical analysis of male income dynamics in the PSID: 1968-1989’, Journal of Econometrics, vol. 96(2), pp. 293-356.

Goeree, J., Holt, C. and Palfrey, T. (2003). 'Risk averse behavior in generalized matching pennies games', Games and Economic Behavior, vol. 45(1), pp. 97-113.

Heckman, J. (1976). 'Estimates of a human capital production function embedded in a life-cycle model of labor supply', in (N. Terlecky, ed.), Household Production and Consumption, pp. 227-264. New York: Columbia University Press.

Heckman, J. and MaCurdy, T. (1982). 'Corrigendum on a life cycle model of female labor Supply', Review of Economic Studies, vol. 49(4), pp. 659-660.

Imai, S. and Keane, M. (2004). 'Intertemporal labor supply and human capital accumulation', International Economic Review, vol. 45(2), pp. 601-642.

Keane, M. (2011). 'Labor supply and taxes', Journal of Economic Literature, vol. 49(4), pp. 961-1075. 
Keane, M. (2009). 'Income taxation in a life-cycle model with human capital', Working Paper \#2011-17, Centre of Excellence in Population Ageing Research (CEPAR), Australian School of Business, University of New South Wales.

Keane, M. (2015). 'Effects of permanent and transitory tax changes in a life-cycle labor supply model with human capital', International Economic Review, vol. 56(2), pp. 485-503.

Keane M. and Rogerson, R. (2015). 'Reconciling micro and macro labor supply elasticities: a structural perspective', in (K. Arrow and T. Bresnahan, eds.), Annual Review of Economics, vol. 7, pp. 89-117.

Keane, M. and Rogerson R. (2012). 'Micro and macro labor supply elasticities: a reassessment of conventional wisdom', Journal of Economic Literature, vol. 50(2), pp. 464-76.

Keane, M. and Wolpin, K. (2010). 'The role of labor and marriage markets, preference heterogeneity, and the welfare system in the life cycle decisions of black, Hispanic and white women', International Economic Review, vol. 51(3), pp. 851-892.

Keane, M. and Wolpin, K. (2001). 'The effect of parental transfers and borrowing constraints on educational attainment', International Economic Review, vol. 42(4), pp. 10511103.

Keane, M. and Wolpin, K. (2000). 'Equalizing race differences in school attainment and labor market success', Journal of Labor Economics, vol. 18(4), pp. 614-52.

Keane, M. and Wolpin, K. (1997). 'The career decisions of young men', Journal of Political Economy, vol. 105(3) pp. 473-522.

Kimmel J. and Knieser, T. (1998). 'New evidence on labor supply: employment vs. hours elasticities by sex and marital status', Journal of Monetary Economics, vol. 42(2), pp. 289-301.

Low, H. and Maldoom D. (2004). 'Optimal taxation, prudence and risk-sharing', Journal of Public Economics, vol. 88(3-4), pp. 443-464.

MaCurdy, T. (1981). 'An empirical model of labor supply in a life-cycle setting', Journal of Political Economy, vol. 89(6), pp. 1059-1085.

MaCurdy, T. (1983). 'A simple scheme for estimating an intertemporal model of labor supply and consumption in the presence of taxes and uncertainty', International Economic Review, vol. 24(2), pp. 265-289.

McGrattan, E. and Rogerson R. (1998). 'Changes in hours worked since 1950', Federal Reserve bank of Minneapolis Quarterly Review, vol. 22(1), pp. 2-19.

Mincer, J. (1958). 'Investment in human capital and personal income distribution', Journal of Political Economy, vol. 66(4), pp. 281-302.

Mirrlees, J. (1971). 'An exploration in the theory of optimal income taxation', The Review of Economic Studies, vol. 38(2), pp. 175-208. 
Pencavel, J. (1986). 'Labor supply of men: a survey,' in (O. Ashenfelter and Layard R., eds.), Handbook of Labor Economics, vol. 1, pp. 3-102, Amsterdam: North-Holland.

Prescott, E. (1986). 'Theory ahead of business cycle measurement', Federal Reserve Bank of Minneapolis Quarterly Review, vol. 10(4), pp. 9-22.

Prescott, E. (2006). 'Nobel lecture: the transformation of macroeconomic policy and research', Journal of Political Economy, vol. 114(2), pp. 203-235.

Prescott E., Rogerson R., and Wallenius J. (2009). 'Lifetime aggregate labor supply with endogenous workweek length', Review of Economic Dynamics, vol. 12(1), pp. 23-36.

Purcell, P. (2009). Older Workers: Employment and Retirement Trends, Congressional Research Service, Washington, D.C., Available at: www.crs.gov.

Rogerson, R. and Wallenius J. (2009). 'Micro and macro elasticities in a life cycle model with taxes', Journal of Economic Theory, vol. 144(6), pp. 2277-2292.

Saez, E., Slemrod J. and Giertz, S. (2012). 'The elasticity of taxable income with respect to marginal tax rates: a critical review', Journal of Economic Literature, vol. 50(1), pp. 3-50.

Shaw, Katherine (1989). 'Life-cycle labor supply with human capital accumulation. International Economic Review, vol. 30(2), pp. 431-56.

Van der Klaauw, W. and Wolpin K. (2008). 'Social security and the retirement and savings behavior of low income households', Journal of Econometrics, vol. 145(1-2), pp. 2142. 


\section{Figure 1}

\section{Hours, Wages and Price of Time over the Life-Cycle}

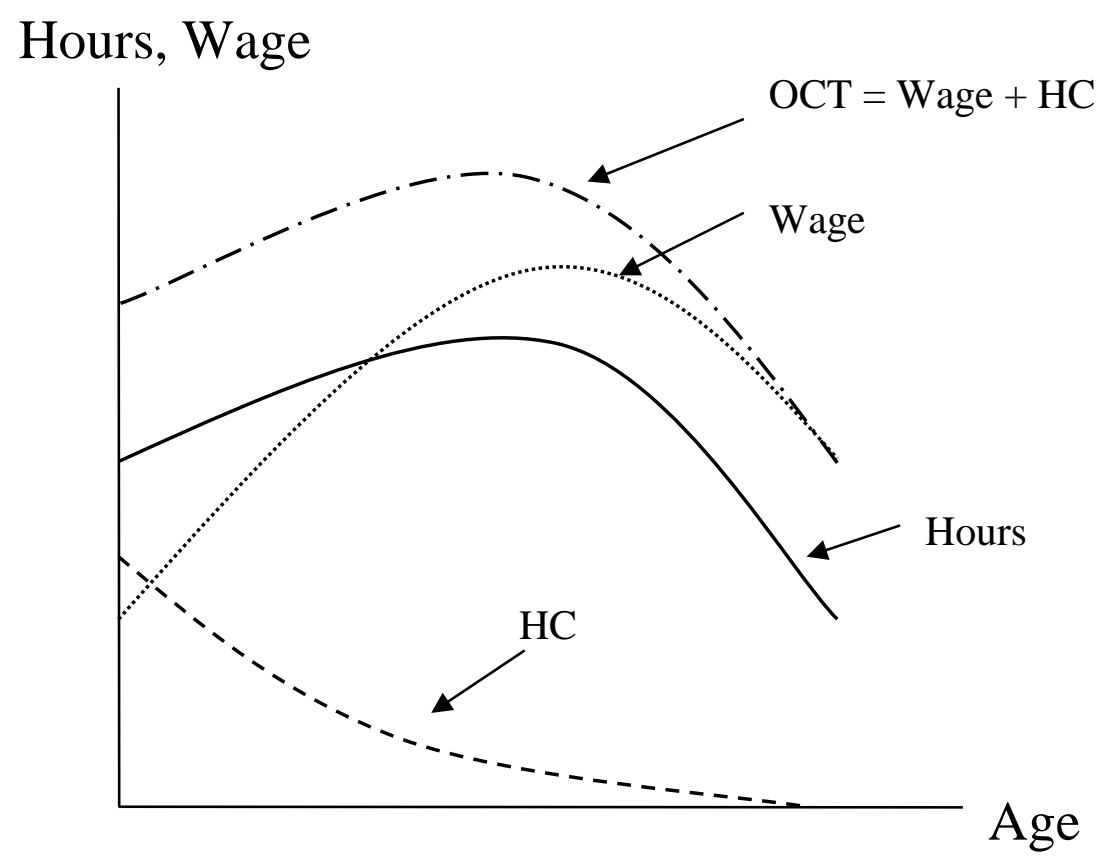

Note: This figure plots the components of the first order condition for labour supply generated by the life-cycle model with human capital: $\beta h_{t}^{\gamma} / C^{\eta}=w_{t}\left(1-\tau_{t}\right)+\alpha w F_{t}$. We have Wage $\equiv w_{t}\left(1-\tau_{t}\right)$, the "human capital term" $H C \equiv \alpha w F_{t}$, and the "opportunity cost of time" OCT $\equiv$ Wage + HC. Note that the term $\mathrm{HC}$ captures the return to an hour of work experience, in terms of increased present value of future wages. 
Table 1

Labor Supply Responses to Tax Changes, Case of $\eta=-.75$

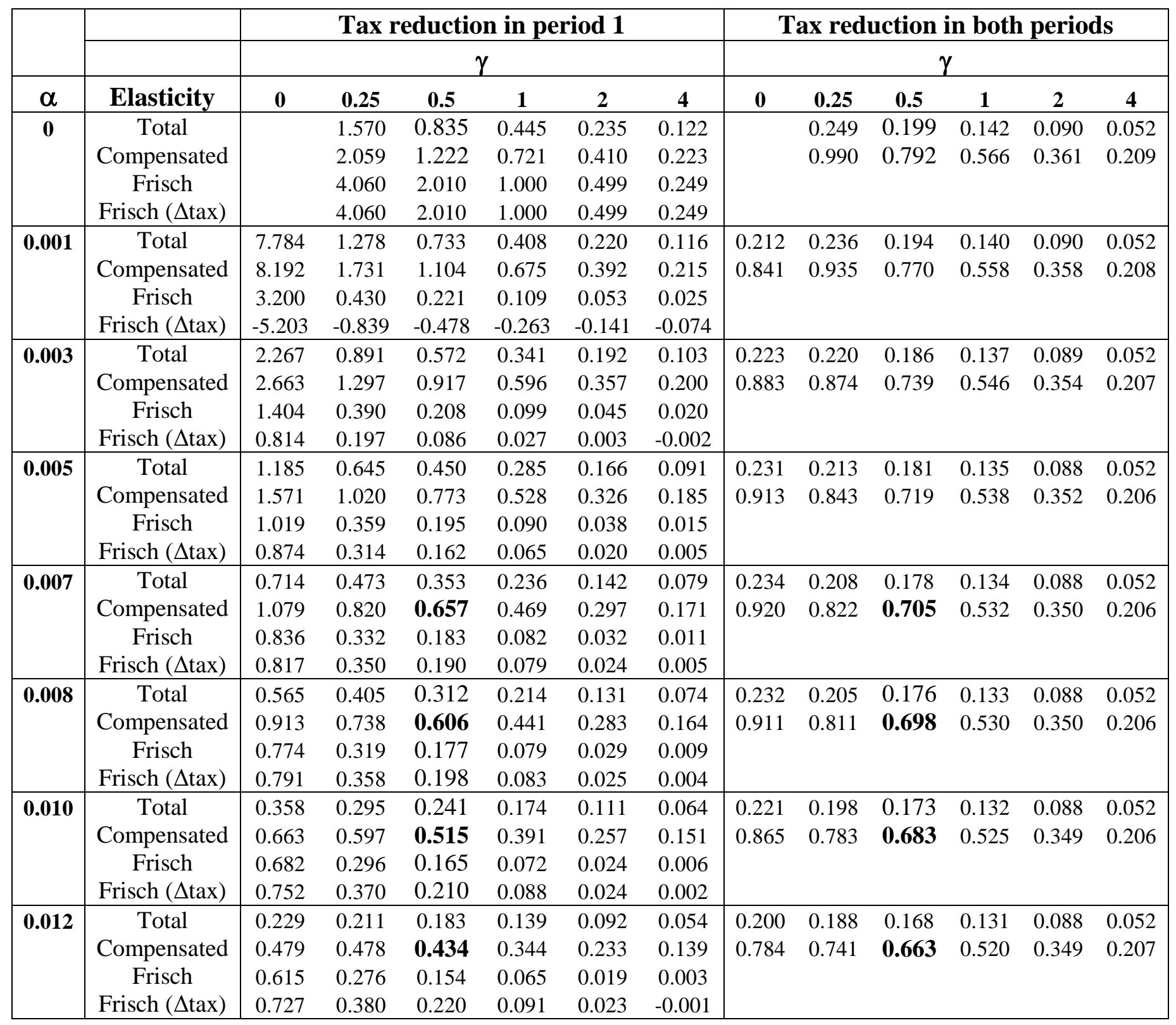

Note: $\eta=-.75$ is the Imai and Keane (2004) estimate. The "Total" elasticity is the uncompensated. The "Frisch" elasticity refers to the estimate obtained using the conventional method of regressing the log hours change on the log earnings change, using the simulated data. In the rows labelled simply "Frisch" the estimate is obtained from simulated data where the tax rate is equal in the two periods. In the rows labelled "Frisch (tax)" the Frisch estimate is obtained using data that contain a tax cut at $t=1$. The figures in bold are cases where, for my preferred value of $\gamma=0.5$, permanent tax effects exceed transitory tax effects. 
Table 2

Labor Supply Responses to Tax Changes, Case of $\eta=-.5$

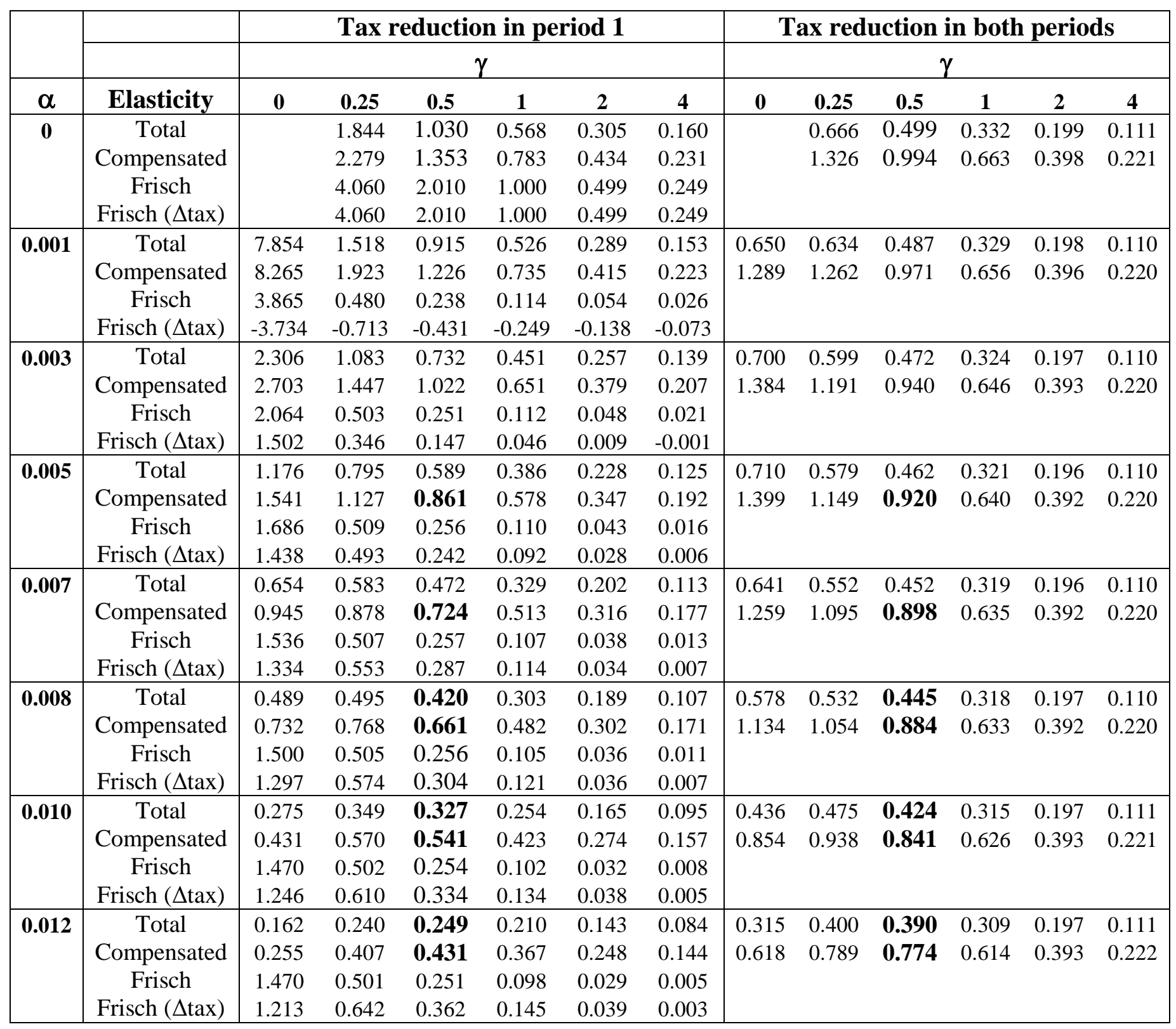

Note: $\eta=-.5$ is the Keane and Wolpin (2001) estimate. The "Total" elasticity is the uncompensated. The "Frisch" elasticity refers to the estimate obtained using the conventional method of regressing the log hours change on the log earnings change, using the simulated data. In the rows labelled simply "Frisch" the estimate is obtained from simulated data where the tax rate is equal in the two periods. In the rows labelled "Frisch (tax)" the Frisch estimate is obtained using data that contain a tax cut at $t=1$. The figures in bold are cases where, for my preferred value of $\gamma=0.5$, permanent tax effects exceed transitory tax effects. 
Table 3

Short-Run Labour Supply Responses to Taxes in the Imai-Keane Model

\begin{tabular}{ccccc}
\hline & \multicolumn{2}{c}{ Transitory } & \multicolumn{2}{c}{ Permanent (Unanticipated) } \\
\hline Age & Unanticipated & $\begin{array}{c}\text { Anticipated } \\
\text { (Frisch) }\end{array}$ & $\begin{array}{c}\text { Uncompensated } \\
\text { (Marshall) }\end{array}$ & $\begin{array}{c}\text { Compensated } \\
\text { (Hicks) }\end{array}$ \\
$\mathbf{2 0}$ & $\mathbf{0 . 3 0}$ & $\mathbf{0 . 3 0}$ & 0.14 & $\mathbf{0 . 6 4}$ \\
$\mathbf{2 5}$ & $\mathbf{0 . 3 6}$ & $\mathbf{0 . 3 6}$ & 0.12 & $\mathbf{0 . 5 4}$ \\
$\mathbf{3 0}$ & $\mathbf{0 . 4 4}$ & $\mathbf{0 . 4 4}$ & 0.12 & $\mathbf{0 . 4 8}$ \\
$\mathbf{3 5}$ & 0.52 & 0.52 & 0.10 & 0.46 \\
$\mathbf{4 0}$ & 0.64 & 0.66 & 0.14 & 0.46 \\
$\mathbf{4 5}$ & 0.76 & 0.84 & 0.20 & 0.56 \\
$\mathbf{5 0}$ & 0.94 & 1.06 & 0.46 & 0.84 \\
$\mathbf{5 5}$ & 1.24 & 1.44 & 1.06 & 1.44 \\
$\mathbf{6 0}$ & $\mathbf{1 . 7 4}$ & $\mathbf{1 . 9 6}$ & 1.88 & $\mathbf{2 . 0 9}$ \\
\hline
\end{tabular}

Note: All figures are elasticities of current hours with respect to tax changes. The "transitory" increase only applies for one year at the indicated age. In the "anticipated" case this has no wealth effect, so it is a pure Frisch effect. The "permanent" tax increases take effect (unexpectedly) at the indicated age and last until age 65. In the "compensated" case the proceeds of the tax (in each year) are distributed back to agents in lump sum form. Figures in bold are cases where permanent tax effects exceed transitory tax effects.

\section{Table 4}

\section{Lifetime Effects of a Permanent Tax Increase on Labour Supply}

\begin{tabular}{ccc}
\hline Age & Uncompensated & Compensated \\
\hline $\mathbf{2 0}$ & 0.14 & 0.64 \\
$\mathbf{3 0}$ & 0.14 & 0.66 \\
$\mathbf{4 0}$ & 0.18 & 0.84 \\
$\mathbf{4 5}$ & 0.24 & 1.14 \\
$\mathbf{5 0}$ & 0.42 & 1.74 \\
$\mathbf{6 0}$ & 1.82 & 4.00 \\
Lifetime Hours & & \\
(Ages 20-65) & 0.40 & 1.32 \\
\hline
\end{tabular}

Note: This table compares the baseline simulation of the Imai-Keane (2004) model with an alternative scenario where the tax rate on earnings is permanently higher. The increase is in effect from the first period (age 20) until the terminal period (age 65). The table reports both the uncompensated case and the case where the proceeds of the tax (in each year) are distributed back to agents in lump sum form. 